\title{
Is Video Laryngoscopy the Optimal Tool for Successful Intubation in a Neonatal Simulation Setting? A Single-Center Experience
}

\author{
Iram Musharaf, MBBS ${ }^{1} \odot$ Sibasis Daspal, $\mathrm{MD}^{1}$ John Shatzer, $\mathrm{PhD}^{2}$ \\ ${ }^{1}$ Division of Neonatology, Department of Pediatrics, University of \\ Address for correspondence Iram Musharaf, MBBS, Neonatal \\ Saskatchewan, Saskatoon, Saskatchewan, Canada \\ 2 Johns Hopkins University School of Education, Baltimore, \\ Maryland \\ Intensive Care Unit, Department of Pediatrics, Royal University \\ Hospital, 103 Hospital Drive, Saskatoon, SK S7N 0W8, Canada \\ (e-mail: irm944@mail.usask.ca).
}

Am J Perinatol Rep 2020;10:e5-e10.

\begin{abstract}
Keywords

- direct laryngoscopy

- intubation

- neonatal

- simulation

- video laryngoscopy
\end{abstract}

Endotracheal intubation is an imperative skill for resuscitation in a critical care setting. Due to the increased use of noninvasive ventilation, ${ }^{1}$ changes in recommendations for intubating meconium-stained infants, ${ }^{2,3}$ and presence of multiple health care providers, the opportunities for residents and other health care professionals to practice intubation in real-life situations are decreasing. All of these factors are contributing to a low intubation success rate. As a result, residents do

received

May 1, 2019

accepted after revision

August 13, 2019
DOI https://doi.org/

10.1055/s-0039-3400970. ISSN 2157-6998. not have adequate opportunities to achieve competence. ${ }^{4}$ Multiple failed intubation attempts may actually contribute to decreased success rate. ${ }^{5}$

Intubations by inexperienced personnel may require an increased number of intubation attempts associated with adverse events. A multicenter observational cohort study in pediatric intensive care units identified that pediatric residents require extensive training before intubating real
Copyright $@ 2020$ by Thieme Medical Publishers, Inc., 333 Seventh Avenue, New York, NY 10001, USA. Tel: +1(212) 760-0888.
License terms

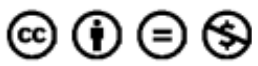


patients. ${ }^{6}$ Refresher training sessions improve intubation success rate in both inexperienced and experienced health professionals. ${ }^{7}$ Repeated procedural simulation workshops boost residents' confidence and competence, regardless of the year of training. ${ }^{8,9}$

For decades, direct laryngoscopy (DL) has been considered the gold standard for intubation. Video laryngoscopy (VL) is an indirect laryngoscopy when a magnified view of the airway is displayed on a monitor. It has been associated with a higher success rate with nonexpert trainees and difficult airway situations. $^{10,11}$ Improved intubation success rates may be explained by simultaneous feedback from instructors who share the video laryngoscope screen with the learner. ${ }^{12}$

There are controversial data among studies focused on the role of VL in training residents and other nonexpert trainees. At the same time, the role of VL in assessment and maintenance of skills by trained health care professionals remains unclear.

The purpose of this study was to compare the success rates of intubation by video and direct laryngoscopes among professionals with different level of experience in a simulated setting in order to find the preferred method for training residents and maintenance of skills by other health care professionals, with the aim of including it in a simulation curriculum subsequently.

\section{Methods}

\section{Study Design}

We conducted a nonrandomized crossover trial in simulation to compare intubation experience with direct and video laryngoscopes (GlideScope) at the Royal University Hospital, Saskatoon in March 2017. The study had been approved as exempt from review by the University of Saskatchewan Research Ethics Board in August 2016 and by the Johns Hopkins University Homewood Institutional Review Board in January 2017. Oral consent was obtained from all participants.

\section{Equipment and Materials}

The devices used for the study were a direct laryngoscope and GlideScope video laryngoscope. Miller size 1 blade and GVL1 single use STAT were used for intubation with direct and video laryngoscopes, respectively. All intubations were performed using an endotracheal tube with an internal diameter of $3.5 \mathrm{~mm}$ and a stylet. The endotracheal tubes were lubricated before the procedure. The manikin used for the study was SimNewB by Laerdal. A self-inflating bag and stethoscope were used to confirm placement.

\section{Participants}

Twenty-six participants working in neonatal intensive care unit at the Royal University Hospital, Saskatoon were recruited. Participants were divided into three groups based on the frequency of intubation: (1) residents (low frequency); (2) transport nurses and respiratory therapists (medium frequency); and (3) neonatal nurse practitioners and physicians (high frequency). There were eight, nine, and nine participants in groups 1, 2, and 3, respectively (-Fig. 1). The demographic characteristics of participants are described in -Table $\mathbf{1}$.

\section{Procedures}

The participants watched a short video on the use of GlideScope. They received a brief demonstration by one of the investigators on the use of both laryngoscopes on manikin. They were not allowed to practice before recruitment. The participants were asked to intubate with direct and video laryngoscopes in a nonrandom sequence. There were two data collection instruments; one was the data collection sheet that was filled in by the observer as the participants performed the procedure. The observer used a stopwatch to measure the time taken for successful intubation. The second instrument was the survey questionnaire given to participants after the study. The data recorded included successful first attempt intubation, intubation time, number of attempts, laryngoscope preference, selfreported confidence, years of experience, recent life support training, etc. Both instruments were developed after reviewing literature on crossover studies comparing the two kinds of laryngoscopes. The data collection instruments were finalized after the authors reached a consensus. There were only two individuals who observed the participants and most of the times both were present, only one observer recorded the data.

\section{Outcomes}

The primary outcome of the study was successful first attempt intubation that was defined as correct tube placement confirmed by chest rise and auscultation. The secondary outcomes included intubation time (in seconds, from the time of insertion of laryngoscope blade into the manikin's mouth to its removal) and laryngoscope preference for learning.

\section{Statistical Analysis}

The data were compiled and recorded on a Microsoft Excel spreadsheet and analyzed by the Statistical Package for Social Sciences (SPSS) v23 for Windows. Effect size was calculated through Microsoft Excel. Wilcoxon's signed rank test was used to analyze the time to intubation. Successful first attempt intubation and number of attempts were reported as numbers and percentages. A chi-square test was used to analyze the laryngoscope preference. A $p$-value of $\leq 0.05$ was considered significant. Results were presented as medians, interquartile range (IQR), numbers, and percentages as the data were not normally distributed.

\section{Results}

\section{Successful First Attempt Intubation}

All participants were able to intubate successfully with both laryngoscopes in first attempt except one in group 3, who required three attempts with the direct laryngoscope and one with the video laryngoscope (-Table 2 ).

\section{Intubation Time in Seconds}

Group 1 residents: Intubation time was longer with direct laryngoscope as compared with the video laryngoscope, although this difference was not statistically significant $(p=0.779)$, with an effect size of 0.1 (-Table 3, - Fig. 2). The median time was 22 seconds (IQR 14.3-22.8 seconds) in the direct arm and 12.5 seconds (IQR 10.3-38.8 seconds) in 


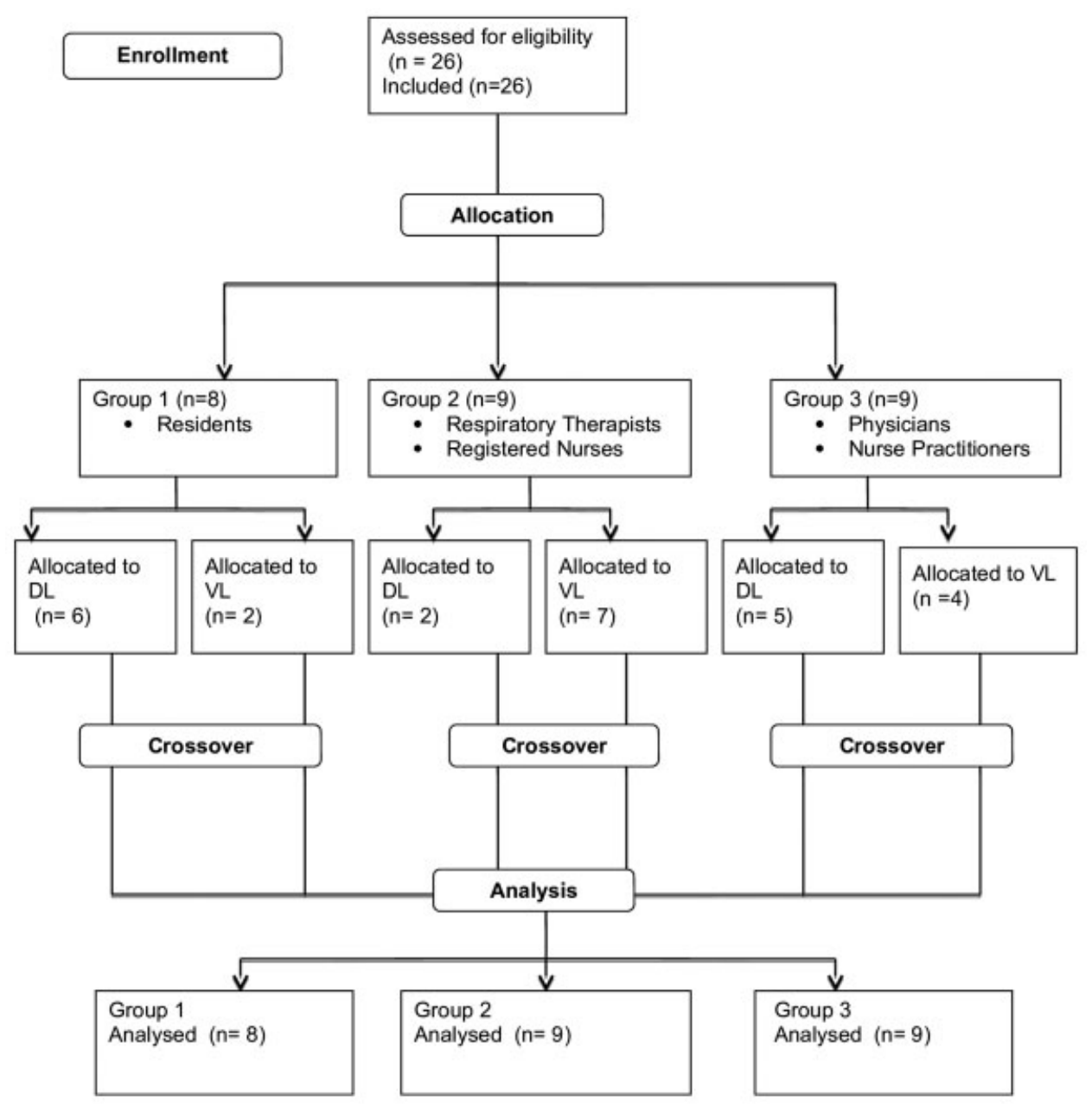

Fig. 1 Flow chart of recruitment and design based on CONSORT statement. DL, direct laryngoscopy; VL, video laryngoscopy.

the video arm. Two participants took longer than 30 seconds to intubate with the video laryngoscope.

Group 2 respiratory therapists (RTS) and registered nurses $(R N s)$ : Intubation time was longer with the direct laryngoscope than with the video laryngoscope, this difference was not statistically significant $(p=0.476)$ with an effect size of 0.36 (-Table 3, - Fig. 2). The median time was 17 seconds (IQR 8-21 seconds) in the direct arm and 12 seconds (IQR 9-16.5 seconds) in the video arm. All participants intubated in $<30$ seconds with both laryngoscopes.

Group 3 physicians (MDs) and neonatal nurse practitioners (NNPs): Intubation time was significantly shorter with the direct laryngoscope when compared with the video laryngoscope $(p=0.024)$ with an effect size of 1.25 (-Table 3, -Fig. 2). The median time was 11 seconds (IQR 17.515.5 seconds) in the direct arm and 15 seconds (IQR 11.536 seconds) in the video arm. All participants intubated with the direct laryngoscope in $<30$ seconds, while two took longer than 30 seconds with the video laryngoscope (only successful attempts were included for this analysis).

\section{Laryngoscope Preference}

Group 1: Six out of eight participants (75\%) preferred VL for learning $(p=0.044)$ (-Table 4, -Fig. 3).
Group 2: Six out of eight (66.7\%) chose VL for learning, although the difference was not statistically significant $(p=0.097)$ (-Table 4, - Fig. 3).

Group 3: Five out of nine participants (55.6\%) preferred both laryngoscopes for learning $(p=0.739)$ (-Table 4 , -Fig. 3).

\section{Discussion}

The opportunities for neonatal intubation for pediatric trainees have reduced significantly over the years with a similar effect on the success rate. ${ }^{4}$ A retrospective study of critical procedures performed in pediatric emergency department showed that if clinical experience is the exclusive source of learning, then fellows' achievement of competence is questionable along with increased risk of skill decline in faculty. ${ }^{13}$

Current data about VL and DL as teaching tools for successful intubation in simulation setting are controversial. According to a systematic review, nonexpert users had faster intubation time and a better success rate with a video laryngoscope. ${ }^{10} \mathrm{~A}$ meta-analysis showed that time to intubation is longer with VL when compared with DL. ${ }^{14}$ On the contrary, a randomized trial comparing the DL and VL for difficult airways by expert intubators showed that VL 
Table 1 Demographic characteristics

\begin{tabular}{|c|c|c|c|}
\hline & $\begin{array}{l}\text { Group 1, } \\
n(\%)\end{array}$ & $\begin{array}{l}\text { Group 2, } \\
n(\%)\end{array}$ & $\begin{array}{l}\text { Group } 3 \text {, } \\
n(\%)\end{array}$ \\
\hline Total & 8 & 9 & 9 \\
\hline Male & $4(50)$ & $1(11.1)$ & $4(44.4)$ \\
\hline Female & $4(50)$ & $8(88.9)$ & $5(55.6)$ \\
\hline \multicolumn{4}{|c|}{ Residents (year of training) } \\
\hline 1 & $1(12.5)$ & & \\
\hline 2 & $2(25)$ & & \\
\hline 3 & $4(50)$ & & \\
\hline 4 & $1(12.5)$ & & \\
\hline \multicolumn{4}{|c|}{ Recent resuscitation courses } \\
\hline NRP & $8(100)$ & $9(100)$ & $9(100)$ \\
\hline PALS & $8(100)$ & $2(22.2)$ & $2(22.2)$ \\
\hline ACLS & $1(12.5)$ & $5(55.6)$ & $0(0)$ \\
\hline BLS & $1(12.5)$ & $2(22.2)$ & $0(0)$ \\
\hline \multicolumn{4}{|c|}{ Timing of course taken } \\
\hline$<6$ mo & $2(25)$ & $3(33.3)$ & $2(22.2)$ \\
\hline $6-12 \mathrm{mo}$ & $0(0)$ & $0(0)$ & $0(0)$ \\
\hline$>12 \mathrm{mo}$ & $0(0)$ & $0(0)$ & $1(11.1)$ \\
\hline Unknown & $6(75)$ & $6(66.7)$ & $6(66.7)$ \\
\hline \multicolumn{4}{|c|}{ Years of experience } \\
\hline$<3$ & $5(62.5)$ & $3(33.3)$ & $0(0)$ \\
\hline $3-5$ & $3(37.5)$ & $3(33.3)$ & $1(11.1)$ \\
\hline$>5$ & $0(0)$ & $3(33.3)$ & 8 (88.9) \\
\hline
\end{tabular}

Abbreviations: ACLS, advanced cardiac life support; BLS, basic life support; NRP, neonatal resuscitation program; PALS, pediatric advanced life support.

Table 2 Intubation success and participant satisfaction

\begin{tabular}{|c|l|l|l|}
\hline & $\begin{array}{l}\text { Group 1, } \\
\boldsymbol{n}(\%)\end{array}$ & $\begin{array}{l}\text { Group 2, } \\
\boldsymbol{n}(\%)\end{array}$ & $\begin{array}{l}\text { Group 3, } \\
\boldsymbol{n}(\%)\end{array}$ \\
\hline \multicolumn{4}{|l|}{ Successful intubation at first attempt } \\
\hline Direct & $8(100)$ & $9(100)$ & $8(88.9)$ \\
\hline Video & $8(100)$ & $9(100)$ & $9(100)$ \\
\hline
\end{tabular}

Table 3 Intubation time

\begin{tabular}{|c|c|c|c|}
\hline \multirow{2}{*}{$\begin{array}{l}\text { Intubation } \\
\text { time (s) }\end{array}$} & Group 1 & Group 2 & Group 3 \\
\hline & $\begin{array}{l}\text { Median } \\
\text { (IQR) }\end{array}$ & $\begin{array}{l}\text { Median } \\
\text { (IQR) }\end{array}$ & $\begin{array}{l}\text { Median } \\
\text { (IQR) }\end{array}$ \\
\hline Direct & $\begin{array}{l}22 \mathrm{~s} \\
(14.3-22.8 \mathrm{~s})\end{array}$ & $\begin{array}{l}17 \mathrm{~s} \\
(8-21 \mathrm{~s})\end{array}$ & $\begin{array}{l}11 \mathrm{~s} \\
(7.5-15.5 \mathrm{~s})\end{array}$ \\
\hline Video & $\begin{array}{l}12.5 \mathrm{~s} \\
(10.3-38.8 \mathrm{~s})\end{array}$ & $\begin{array}{l}12 \mathrm{~s} \\
(9-16.5 \mathrm{~s})\end{array}$ & $\begin{array}{l}15 \mathrm{~s} \\
(11.5-36 \mathrm{~s})\end{array}$ \\
\hline$p$-Value & 0.779 & 0.476 & 0.024 \\
\hline $\begin{array}{l}\text { Effect } \\
\text { size (d) }\end{array}$ & 0.1 & 0.36 & 1.25 \\
\hline
\end{tabular}

Abbreviation: IQR, interquartile range.

Note: The significant $p$-value and effect size are in bold. improves the success rate and shortens the intubation time. $^{15}$

In our study, we found out that more experienced providers had the shortest intubation time with the direct laryngoscope, while providers with limited experience showed a tendency toward faster intubation with the video laryngoscope. The median time for successful intubation among residents was almost two times faster with VL as compared with DL that supports the idea that additional visual tool (monitor with magnified view) helps acquisition of new skill (intubation). ${ }^{16}$ For the experienced intubators, the absolute difference between intubation times with two different laryngoscopes was not remarkable but still remained significant ( 11 seconds for DL vs. 15 seconds for $\mathrm{VL})$. The fact that intubation time with VL for this group was the longest among all participants could be explained with interference of already acquired skills (muscular memory) and the need to implement additional visual tool (monitor).

Our other finding was that novice or less experienced providers preferred video laryngoscope for learning. The participants reported that it allowed for a better visualization, guided learning with feedback, and enhanced selfconfidence. Some participants chose both laryngoscopes based on their unique features; VL can be used for difficult airways and DL still remains the standard of care and can be used in situations where video laryngoscope is not available. The learners' preference of VL could be explained with a better glottic view in children ${ }^{17}$ and opportunity to have magnified view on the screen shared by instructor and learner. ${ }^{18}$ A simulated randomized crossover trial showed that novice providers have a higher intubation success rate after receiving video-assisted instruction when compared with traditional instruction. ${ }^{19}$ Another randomized trial, in real patients, demonstrated the highest intubation success rates achieved in novice neonatal intubators when the instructor shared the same video laryngoscope screen. ${ }^{12}$

We did not assess for retention of skills in this group, but another study has shown that pediatric residents were able to maintain their success rates with DL after being taught through VL. ${ }^{11}$

There are a few limitations to this study. The sample size was relatively small; generalizability to a bigger or a different population may not reproduce the same results. Although some participants may represent providers at other institutions such as residents and attending physicians, some members may be unique to this group, that is, transport nurses and respiratory therapists who do not routinely intubate in many centers. Only one type of video laryngoscope was used in this study; the results may be different with other video laryngoscopes.

\section{Conclusion}

In this era of decreased clinical training opportunities, video laryngoscope may serve as a useful tool to teach residents and other novice health care providers. It should be routinely used in simulation by expert health care providers for maintenance of skills and to familiarize them with the 


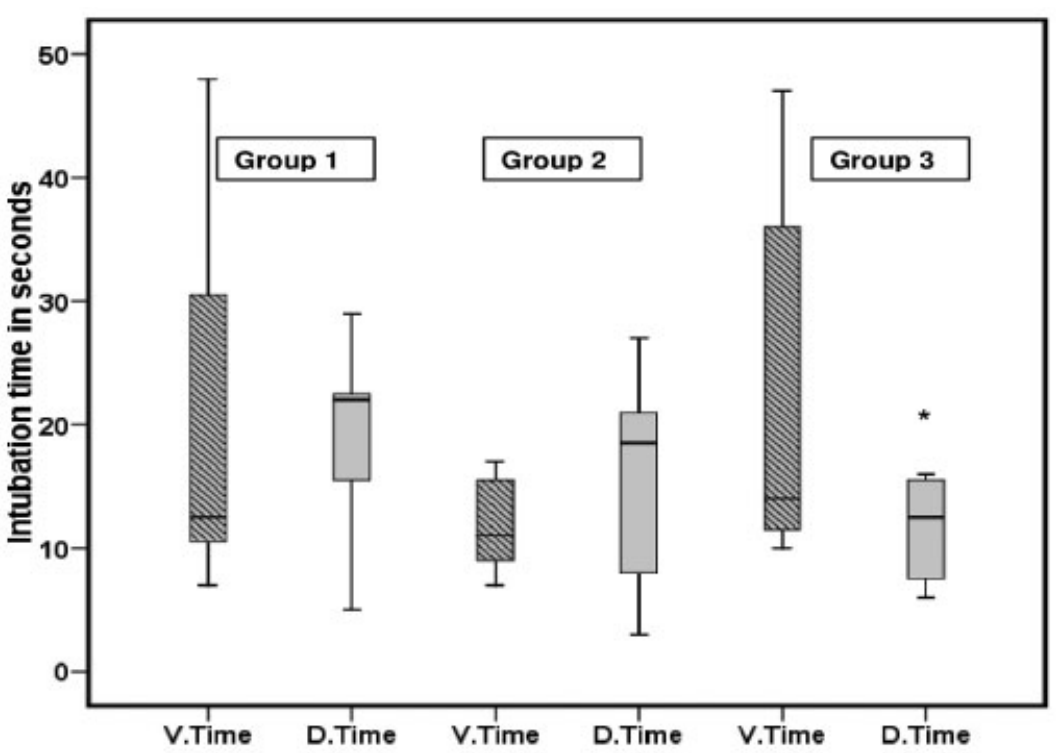

Fig. 2 Intubation time in seconds. D, direct laryngoscope; Group 1, residents ( $p=0.779$ ); group 2, RTs/RNs $(p=0.476)$; group 3, NNPs/MDs $(p=0.024)$; $\mathrm{V}$, video laryngoscope.

Table 4 Laryngoscope preference for learning and ease of use

\begin{tabular}{|l|l|l|l|}
\hline $\begin{array}{l}\text { Laryngoscope } \\
\text { preference }\end{array}$ & $\begin{array}{l}\text { Group 1, } \\
\boldsymbol{n}(\%)\end{array}$ & $\begin{array}{l}\text { Group 2, } \\
\boldsymbol{n}(\%)\end{array}$ & $\begin{array}{l}\text { Group 3, } \\
\boldsymbol{n}(\%)\end{array}$ \\
\hline Direct & $1(12.5)$ & $1(11.1)$ & $0(0)$ \\
\hline Video & $6(75)$ & $6(66.7)$ & $4(44.4)$ \\
\hline Both & $1(12.5)$ & $2(22.2)$ & $5(55.6)$ \\
\hline$p$-Value & $\mathbf{0 . 0 4 4}$ & 0.097 & 0.739 \\
\hline
\end{tabular}

Note: The significant $p$-value is in bold.

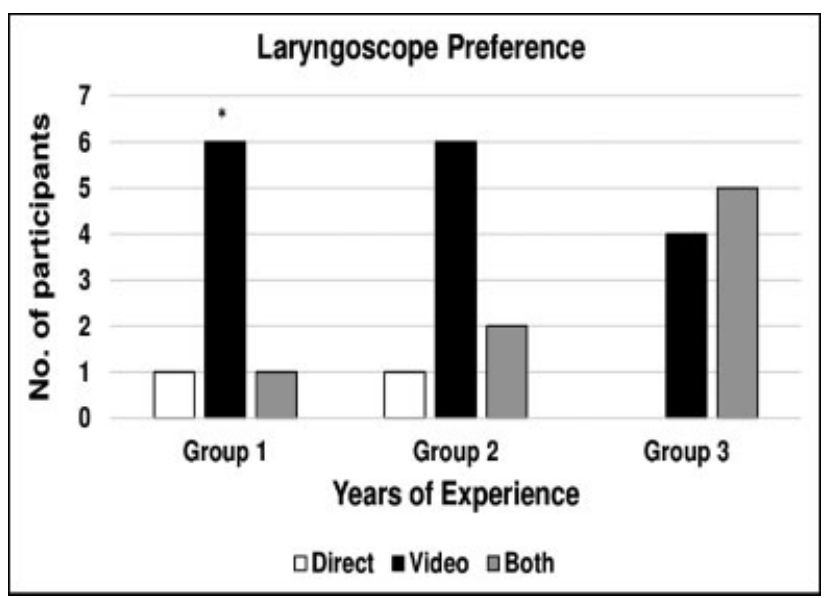

Fig. 3 Laryngoscope preference. Group 1 , residents $(p=0.044)$; group 2, RTs/RNs ( $p=0.097)$; group 3 , NNPs/MDs $(p=0.739)$.

technique so that it can be utilized to manage difficult airways when need arises.

\section{Conflict of Interest}

The authors report no conflict of interest and the study was not funded.

\section{Acknowledgment}

We thank Veronica Samedi, MD, for reviewing the article.

\section{References}

1 Papile L-A, Baley JE, Benitz W, et al; Committee on Fetus and Newborn; American Academy of Pediatrics. Respiratory support in preterm infants at birth. Pediatrics 2014;133(01):171-174

2 Niermeyer S, Kattwinkel J, Van Reempts P, et al. International Guidelines for Neonatal Resuscitation: an excerpt from the Guidelines 2000 for Cardiopulmonary Resuscitation and Emergency Cardiovascular Care: International Consensus on Science. Contributors and Reviewers for the Neonatal Resuscitation Guidelines. Pediatrics 2000;106(03):E29-E29

3 Wyckoff MH, Aziz K, Escobedo MB, et al. Part 13: neonatal resuscitation: 2015 American Heart Association Guidelines Update for Cardiopulmonary Resuscitation and Emergency Cardiovascular Care. Circulation 2015;132(18, Suppl 2):S543-S560

4 Leone TA, Rich W, Finer NN. Neonatal intubation: success of pediatric trainees. J Pediatr 2005;146(05):638-641

5 Goto T, Gibo K, Hagiwara Y, et al; Japanese Emergency Medicine Network Investigators. Multiple failed intubation attempts are associated with decreased success rates on the first rescue intubation in the emergency department: a retrospective analysis of multicentre observational data. Scand J Trauma Resusc Emerg Med 2015;23(01):5

6 Sanders RC Jr, Giuliano JS Jr, Sullivan JE, et al; National Emergency Airway Registry for Children Investigators and Pediatric Acute Lung Injury and Sepsis Investigators Network. Level of trainee and tracheal intubation outcomes. Pediatrics 2013;131 (03):e821-e828

7 Nishisaki A, Scrattish L, Boulet J, et al. Effect of recent refresher training on in situ simulated pediatric tracheal intubation psychomotor skill performance. In: Henriksen K, Battles JB, Keyes MA, et al, eds. Advances in Patient Safety: New Directions and Alternative Approaches. Vol. 3. Rockville, MD: Agency for Healthcare Research and Quality (US); 2008

8 Augustine EM, Kahana M. Effect of procedure simulation workshops on resident procedural confidence and competence. J Grad Med Educ 2012;4(04):479-485

9 Healey A, Sherbino J, Fan J, Mensour M, Upadhye S, Wasi P. A lowfidelity simulation curriculum addresses needs identified by faculty and improves the comfort level of senior internal medicine 
e10 Is Video Laryngoscopy the Optimal Tool? Musharaf et al.

resident physicians with inhospital resuscitation. Crit Care Med 2010;38(09):1899-1903

10 Griesdale DE, Liu D, McKinney J, Choi PT. GlideScope ${ }^{\circledR}$ videolaryngoscopy versus direct laryngoscopy for endotracheal intubation: a systematic review and meta-analysis. Can J Anaesth 2012;59(01):41-52

11 Moussa A, Luangxay Y, Tremblay S, et al. Videolaryngoscope for teaching neonatal endotracheal intubation: a randomized controlled trial. Pediatrics 2016;137(03):e20152156

12 O'Shea JE, Thio M, Kamlin CO, et al. Videolaryngoscopy to teach Nnonatal intubation: a randomized trial. Pediatrics 2015;136 (05):912-919

13 Mittiga MR, Geis GL, Kerrey BT, Rinderknecht AS. The spectrum and frequency of critical procedures performed in a pediatric emergency department: implications of a provider-level view. Ann Emerg Med 2013;61(03):263-270

14 Sun Y, Lu Y, Huang Y, Jiang H. Pediatric video laryngoscope versus direct laryngoscope: a meta-analysis of randomized controlled trials. Paediatr Anaesth 2014;24(10):1056-1065
15 Jungbauer A, Schumann M, Brunkhorst V, Börgers A, Groeben H. Expected difficult tracheal intubation: a prospective comparison of direct laryngoscopy and video laryngoscopy in 200 patients. $\mathrm{Br}$ J Anaesth 2009;102(04):546-550

16 Doane SM, Alderton DL, Sohn YW, Pellegrino JW. Acquisition and transfer of skilled performance: are visual discrimination skills stimulus specific? J Exp Psychol Hum Percept Perform 1996;22 (05):1218-1248

17 Vlatten A, Aucoin S, Litz S, Macmanus B, Soder C. A comparison of the STORZ video laryngoscope and standard direct laryngoscopy for intubation in the Pediatric airway-a randomized clinical trial. Paediatr Anaesth 2009;19(11):11021107

18 Fiadjoe JE, Kovatsis P. Videolaryngoscopes in pediatric anesthesia: what's new? Minerva Anestesiol 2014;80(01):76-82

19 Howard-Quijano KJ, Huang YM, Matevosian R, Kaplan MBSteadman RH. Video-assisted instruction improves the success rate for tracheal intubation by novices. Br J Anaesth 2008;101 (04):568-572 